\title{
Análise do zoneamento e crescimento populacional no bairro Costa Azul em Salvador
}

Lays Britto ${ }^{1}$

\section{Resumo}

Este artigo apresenta uma análise do zoneamento e crescimento populacional do bairro Costa Azul, em Salvador, Bahia, através do estudo da legislação urbanística vigente na cidade e das questões específicas definidas para o bairro, levando em conta suas características ambientais, geográficas, sociais e econômicas, bem como dados sobre a população local e as características diversas que definem sua configuração urbana. Tem como objetivo identificar as medidas previstas na lei de uso do solo e no plano diretor de desenvolvimento urbano para a área, bem como de que maneira essas medidas influenciam na dinâmica urbana do Costa Azul. Também busca fazer uma análise dos dados demográficos da região administrativa em que se encontra o bairro, tendo como base os dados do censo demográfico do ano 2010, disponibilizados pelo IBGE, com destaque para a demanda e o déficit domiciliares, relacionando-os com o processo de produção das edificações no bairro, acesso à moradia pela população, bem como alguns dos desafios relacionados a esta demanda urbana.

Palavras-chave: Costa Azul. Legislação Urbana. Planejamento Urbano. Salvador.

\begin{abstract}
This article presents an analysis of zoning and population growth in the Costa Azul neighborhood in Salvador, Bahia, through the study of current planning legislation in the city and the specific issues identified for the neighborhood, taking into account its environmental, geographical, social and economic, as well as data on the local population and the various characteristics that define its urban setting. It aims to identify the measures in land use law and urban development master plan for the area, and how these measures influence the urban dynamics of the Costa Azul. Also seeks to analyze the demographics Administrative Region you are in the neighborhood, based on the data from the census of 2010 provided by the IBGE, especially household demand and household deficit, relating them to the process production of buildings in the neighborhood, access to housing for the population, as well as some of the challenges related to this urban demand.
\end{abstract}

Keywords: Costa Azul. Urban Legislation. Urban Planning. Salvador.

\footnotetext{
${ }^{1}$ Mestranda no Programa de Pós-Graduação em Desenvolvimento Regional e Urbano (PPDRU) da Universidade Salvador (UNIFACS). laysbritto1@gmail.com
} 


\section{Introdução}

O Costa Azul é um bairro habitado em sua maioria por uma população de classe média de Salvador, localizado na borda marítima, vizinho aos bairros Boca do Rio, Pituba, Stiep e à praia de Armação. Pertence à Região Administrativa 8 da cidade, sendo um bairro predominantemente residencial, constituído, em sua maioria, por edifícios residenciais. Possui também usos complementares para comércio, serviços e institucional, que atendem às necessidades cotidianas da população local. Possui áreas de valor ambiental e paisagístico localizadas no trecho da orla marítima, áreas de interesse social (ZEIS) e uma parte do Centro Municipal mais importante da cidade, o Centro de Camaragibe (CMC).

A região administrativa (RA) é uma subdivisão territorial do município, com objetivos administrativos, de planejamento, gestão e informação. Segundo o Plano Diretor de Desenvolvimento Urbano (PDDU) 2007, essa subdivisão busca uma gestão compartilhada, por meio de uma visão interdisciplinar dos problemas da cidade. Salvador possui 18 regiões administrativas, de acordo com seu PDDU 2007. O bairro Costa Azul faz parte da Região Administrativa 8 (RA VIII), juntamente com os bairros Pituba, Itaigara, Caminho das Árvores, Stiep e Armação. A RA VIII corresponde a 3,62\% (1.123 ha) da área total das regiões administrativas de Salvador, que tem 30.956 ha (Figura 1).

Figura 1 - RA VIII e os bairros que a compõem

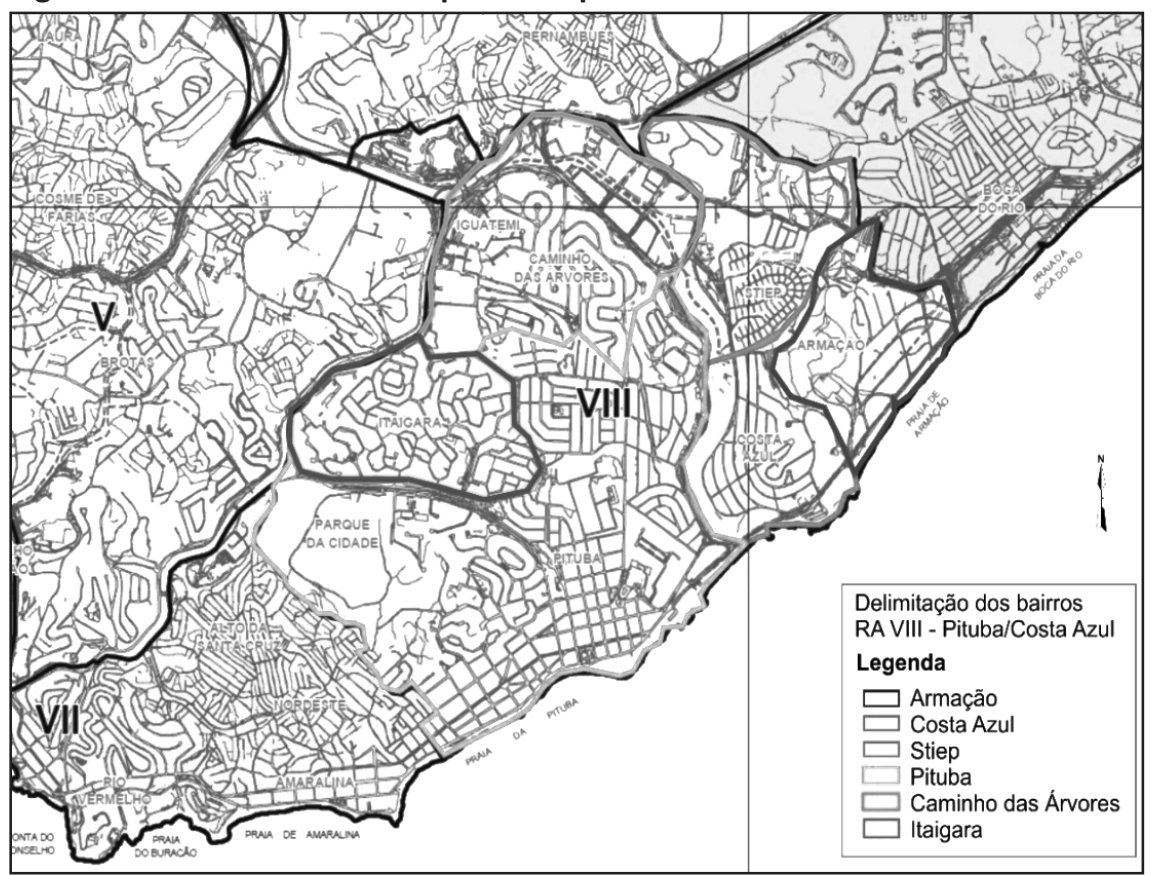

Fonte: Prefeitura Municipal do Salvador (2008). 
O bairro Costa Azul corresponde à aproximadamente $10 \%$ da área da RA VIII, ou seja, cerca de 123,10 ha. É um bairro pequeno e consolidado, com pouquíssimos espaços vazios disponíveis para ocupação urbana (construção de edificações ou espaços públicos como praças e parques).

\section{Descrição urbanística e ambiental}

O Costa Azul é um dos bairros da orla marítima de Salvador. Possui um relevo mais plano na área de borda marítima, que vai aumentando a declividade à medida que se adentra às ruas e quadras que compõem o bairro (sentido norte). Quanto à vegetação, encontra-se o coqueiral, no trecho da orla, presente na praia de Jardim de Allah, e a vegetação decorrente da urbanização das ruas e do parque Costa Azul. Com relação à hidrografia, o bairro é o local da foz do Rio Camarajipe (Figura 2). "O Rio Camarajipe caracteriza-se pela sua utilização como corpo d'água receptor de esgotos sanitários de grande parcela das habitações populares situadas na área de abrangência de sua bacia hidrográfica" (SANTOS et al., 2010, p. 82).

\section{Figura 2 - Delimitação do Bairro Costa Azul}

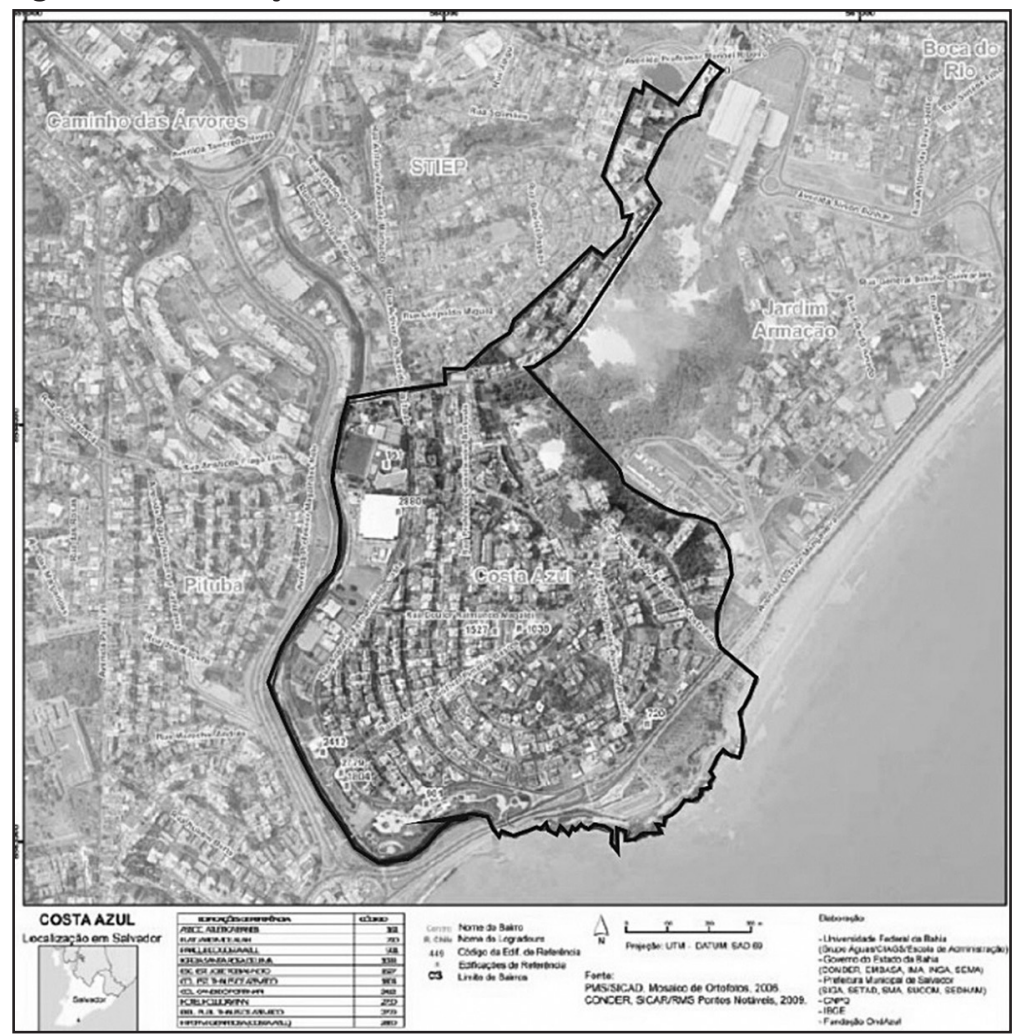

Fonte: Santos et al. (2010). 
Atualmente a população sofre em determinados períodos (principalmente durante as chuvas) com o odor desse rio, por conta da má qualidade de suas águas, prejudicando a saúde da população de modo mais nítido do que o ocorrido diariamente. Essa situação também tem provocado, cada vez mais, uma intensa poluição na praia local, muito usada pela população do Costa Azul, além dos turistas presentes, sobretudo no verão, e nos bairros vizinhos (principalmente os bairros Boca do Rio e Pituba).

Características do desenho geométrico da malha viária e aspectos gerais do parcelamento do solo

Com relação à malha viária, o bairro possui, no sentido oeste, vias com um desenho que acompanha o curso do Rio Camarajipe, com vias internas, praticamente paralelas, sendo cortadas por transversais (Figura 3). A malha possui uma lógica de traçado ortogonal, apesar de trechos que são curvos. Ao mesmo tempo, convergem para uma zona central, que corresponde à área mais alta do bairro. No sentido leste, possui uma malha fragmentada, com ruas que possuem cul de sac e vias apenas de pedestre. Esse traçado reflete o tipo de parcelamento e ocupação do solo presente no bairro.

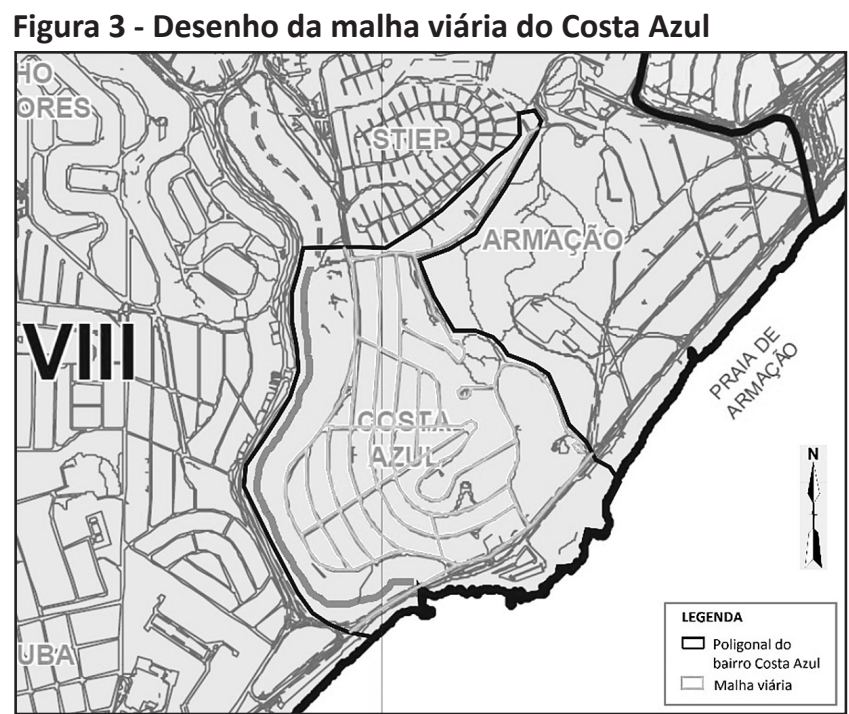

Fonte: Prefeitura Municipal do Salvador (2008).

Quanto ao parcelamento do solo, grande parte do bairro possui lotes retangulares, resultando em quadras também nesse formato, apesar dos desenhos curvos decorrentes das vias, já explicados no item anterior. Quando não são retangulares, possuem forma de algum outro polígono. O lote destacado em vermelho, por exemplo, possui formato triangular e está ocupado por uma igreja (Paróquia Santa Rosa de Lima). Esse tipo de parcelamento está presente no senti- 
do oeste, onde também há uma regularidade na malha viária (Figura 4).

As edificações possuem recuos laterais, frontais e de fundo, como exigem os parâmetros urbanísticos. Quanto ao tamanho, os lotes nesse trecho do bairro variam de 500 até $800 \mathrm{~m}^{2}$, com algumas exceções para mais ou para menos. A ocupação é feita predominantemente por edifícios residenciais e outros edifícios usados para serviços, comércio ou institucional. Existem poucas casas no bairro.

Figura 4 - Trecho do bairro com desenho dos lotes: destaque para a área sem parcelamento legal, área de invasão (delimitada pelo círculo)

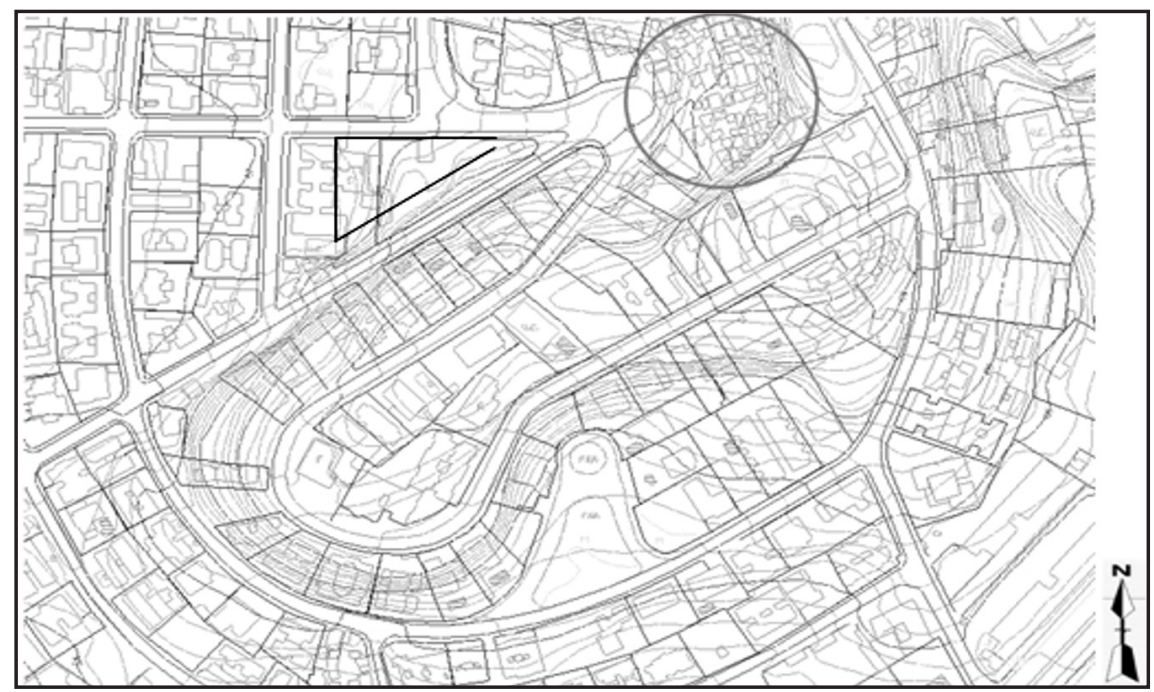

Fonte: Base SICAR, Conder Informs (sem escala definida).

No sentido leste, predominam alguns lotes com conjuntos de edifícios residenciais ao lado de áreas de ocupação ilegal. Essas áreas são terrenos privados que foram invadidos. Possuem edificações muito precárias, com tipologia de favela. São casas que possuem apenas um cômodo, não existindo lotes nem ruas (a população circula por becos estreitos); não há saneamento básico nem infraestrutura urbana, e a população vive em condições subumanas. Nesses locais, também se encontram conjuntos de edifícios com tipologia semelhante a do programa Minha Casa Minha Vida. Nesse lado leste do bairro, também há alguns lotes maiores, que abrigam mais de um edifício residencial por lote. O restante do solo é constituído por terrenos de propriedade particular, que foram invadidos pela população de baixa renda, que hoje convive lado a lado com esses conjuntos residenciais

Ao observar o mapa da Base SICAR, disponibilizado pela Conder, e as imagens aéreas do bairro, fornecidas pelo Google, também é possível notar que ali existem pouquíssimos espaços públicos além do Parque Costa Azul e da própria Orla. Estes são protegidos pela lei como área de proteção ambiental. 


\section{Análise da caracterização zonal}

Nas categorias de zoneamento urbano da Lei de Ordenamento do Uso e Ocupação do Solo (LOUOS) de 1984, o Costa Azul estava inserido em uma das subzonas de concentração de uso residencial (ZR), a ZR 19, composta pelos bairros Costa Azul e Armação. A LOUOS de 1984 permitia, no Costa Azul, os usos unirresidencial, multirresidencial, industrial, comercial, de serviços e misto. Estabelecia dimensões mínimas para os recuos, utilização e ocupação dos terrenos de acordo com cada uso. Esses parâmetros receberam algumas mudanças com o PDDU 2007.

No PDDU 2007, o Costa Azul possui uma caracterização zonal mais abrangente do que a existente na LOUOS de 1984, não mais restrita apenas ao uso do solo. O bairro passa a fazer parte da ZPR 8, Zona Predominantemente Residencial 8, possuindo duas zonas especiais de interesse social (ZEIS): o Recanto Feliz e o Paraíso Azul. Nas zonas não residenciais, possui o Centro Municipal Camaragibe (CMC) e o corredor especial de orla marítima, a Orla Atlântica, que corresponde à Avenida Otávio Mangabeira (Figura 5).

\section{Figura 5 - Zoneamento segundo o PDDU 2007}

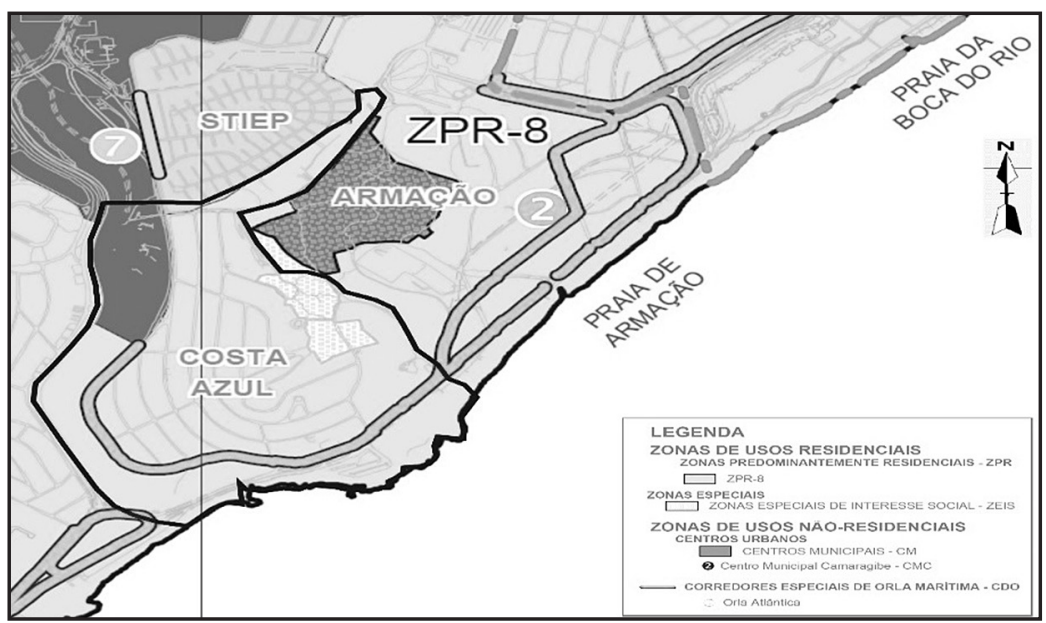

Fonte: Prefeitura Municipal do Salvador (2008).

Com relação ao sistema de áreas de proteção ambiental e cultural (SAVAM), grande parte do bairro está classificada como área de borda marítima. Possui duas áreas de Proteção Cultural e Paisagística (APCP), que correspondem ao Jardim de Allah e ao Parque Costa Azul (Figura 6). 


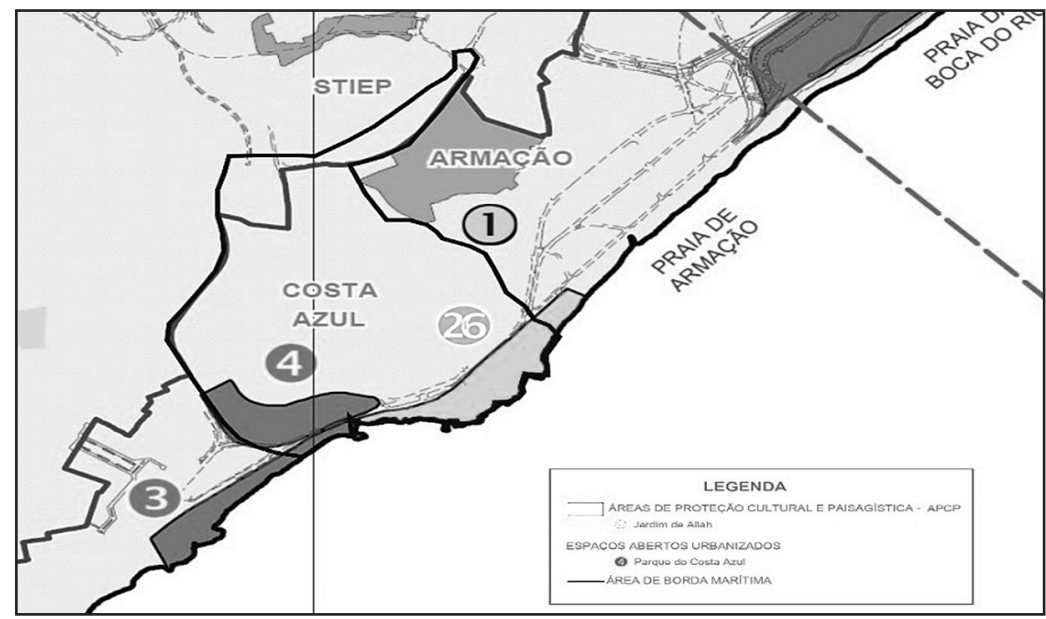

Fonte: Prefeitura Municipal do Salvador (2008).

Segundo o PDDU 2007, o Costa Azul está situado na ZPR 8, Zona Predominantemente Residencial, que é uma subcategoria das Zonas de Uso Residenciais. Para essas zonas, estão previstos na lei Parâmetros Urbanísticos de Controle do Uso e Ocupação do Solo, a fim de garantir a qualidade da moradia e minimizar os conflitos decorrentes dos usos.

Além da Zona Predominantemente Residencial (ZPR), o Costa Azul também possui duas Zona Especial de Interesse Social (ZEIS). As ZEIS são zonas que precisam de critérios específicos para controle e ordenamento do solo, por conta de suas particularidades socioespaciais e urbanísticas. As ZEIS são uma subcategoria das Zonas Especiais, e são zonas que necessitam de regularização fundiária e urbanística, além de produção, manutenção ou qualificação das habitações de interesse social (HIS) e urbanístico (PREFEITURA MUNICIPAL DO SALVADOR, 2008).

\section{Parâmetros urbanísticos}

As diretrizes previstas para as ZEIS têm como objetivo estruturar esses espaços informais e integrá-los ao contexto urbano, garantindo condições de habitabilidade para sua população. Com relação às restrições de ocupação do solo, ficam estabelecidos os parâmetros previstos na lei $n^{\circ}$ 3592/85 para as Áreas de Preservação Socioecológica, além dos usos do grupo CS-1 presentes na tabela IV.3 (subcategoria de uso comercial e de serviço) da lei 3377/84, mais as modificações posteriores, que correspondem ao coeficiente de aproveitamento. 0 PDDU estabelece para as ZEIS apenas o Coeficiente de Aproveitamento Básico (CAB) de 1,50.

Com relação às restrições de ocupação do solo, ficam estabelecidos os parâmetros previstos na lei $\mathrm{n}^{\circ} 3377 / 84$, com as modificações posteriores, que são os coeficientes de aproveitamento. O PDDU 2007 estabelece, para a ZPR 8, o CAB 
de 2,0 e o Coeficiente de Aproveitamento Máximo (CAM) de 3,0. Com relação ao corredor especial de orla marítima, no caso do Costa Azul e da Orla Atlântica, o PDDU estabelece que os coeficientes de aproveitamentos (CAB e CAM) devem ser os mesmos estabelecidos para a zona que a avenida atravessa (cada trecho da via de acordo com o bairro onde está inserida). Nessas duas principais avenidas, localizam-se os pontos de ônibus dentro do bairro (Figura 7).

Figura 7 - Sistema de Transporte no Costa Azul

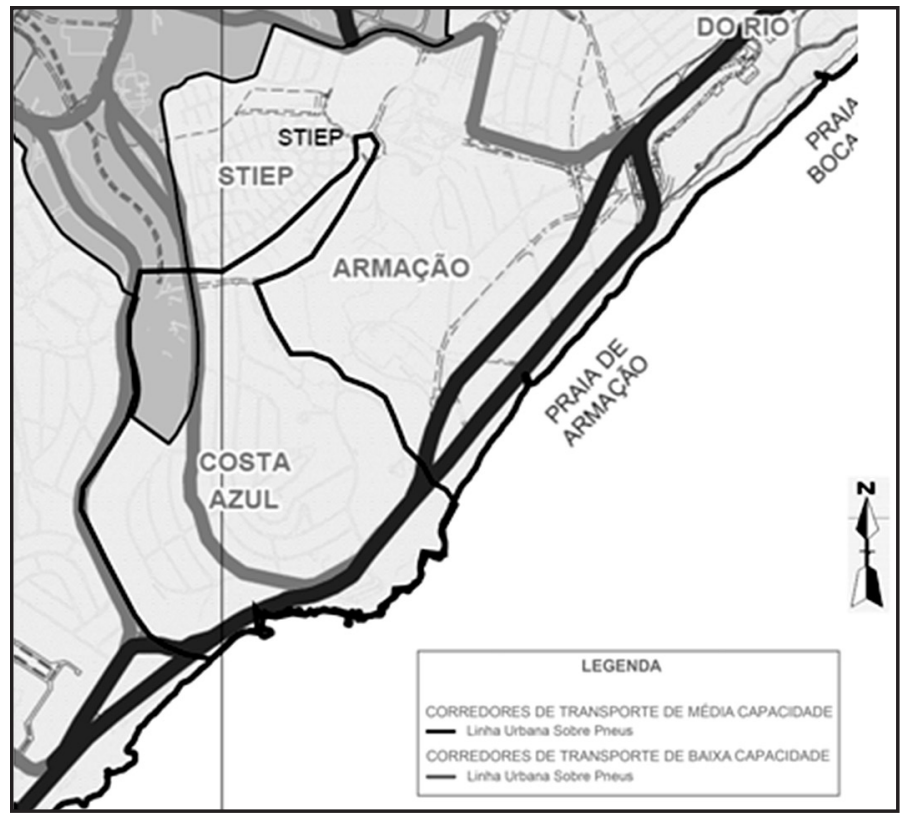

Fonte: Prefeitura Municipal do Salvador (2008).

Quanto ao transporte público para essa área da cidade, está previsto um atendimento à população apenas através de ônibus. Quanto ao sistema viário, o bairro possui ruas arterial e coletora. A via arterial existente é a Avenida Otávio Mangabeira, e as coletoras são a Avenida Arthur Azevedo Machado e a Rua Adelaide Fernandes da Costa. Não estão previstas construção nem duplicação de novas vias para o bairro (Figura 8).

O Costa Azul também possui zona de uso não residencial, que corresponde ao Centro Municipal de Camaragibe (CMC). Segundo o PDDU 2007, os centros municipais são zonas para as quais convergem os principais fluxos que estruturam o ambiente urbano. O Centro Municipal Camaragibe é o principal centro de negócios da cidade (financeiro, de serviços e comércio), possui o terminal interurbano de transporte rodoviário de passageiros, sendo interligado por vias arteriais importantes da cidade, ou seja, possui um sistema viário estrutural. Para esse centro, o Plano Diretor prevê diretrizes com o objetivo de garantir a qualidade dos espaços que o integram, sua infraestrutura, para que as atividades existentes 
nesse local possam continuar se desenvolvendo e também se proteja o patrimônio imobiliário.

Figura 8 - Sistema Viário no Costa Azul

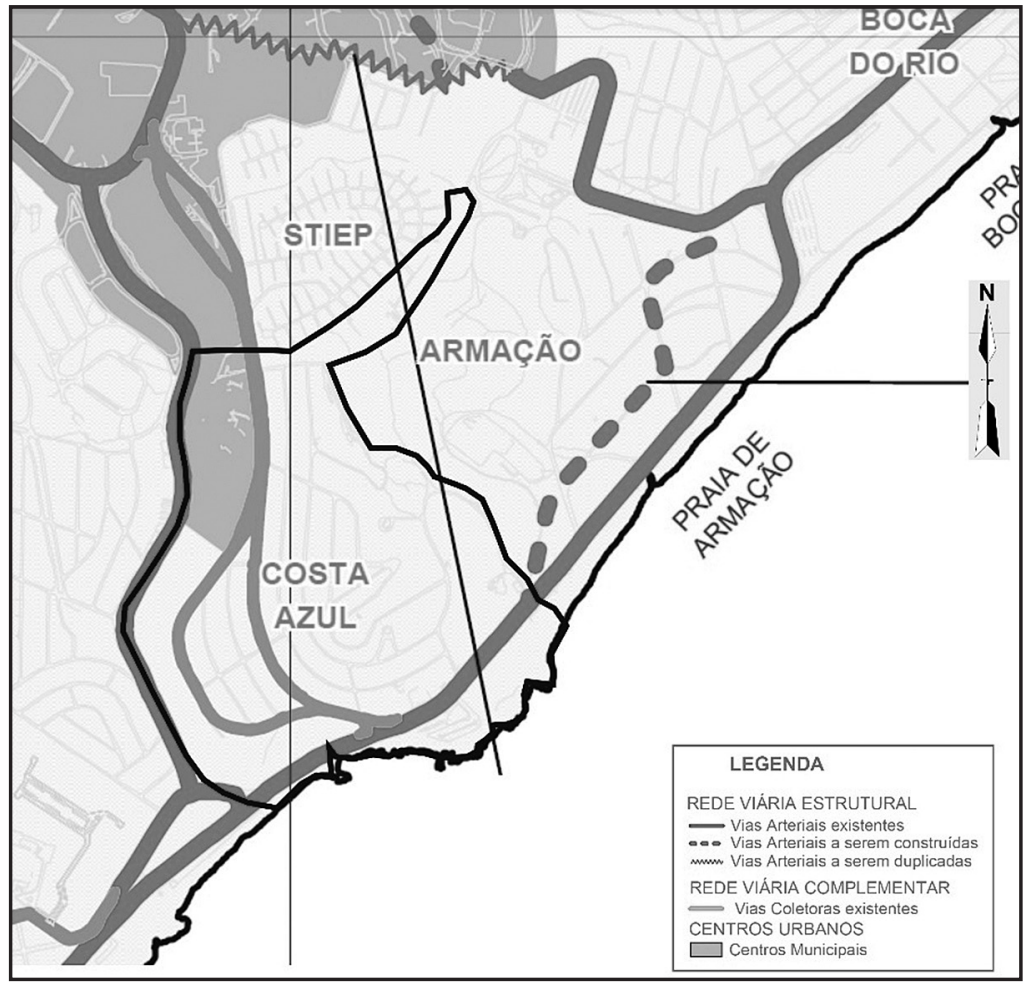

Fonte: Prefeitura Municipal do Salvador (2008).

Para isso, prevê a elaboração de um Plano Urbanístico para requalificação. Algumas diretrizes são melhorias das condições de acessibilidade e circulação da população e prioridade para o transporte coletivo (PREFEITURA MUNICIPAL DO SALVADOR, 2004).

\section{Análise do crescimento demográfico}

Os estudos da Prefeitura de Salvador com relação à população e à densidade populacional bruta por macrozonas e regiões administrativas (Quadro/Tabela A.72.1 - PDDU 2004) mostram que a RA VIII (Região Administrativa 8 - Pituba/ Costa Azul) possuía uma população de 105.105 habitantes no ano 2000, valor que passaria para 140.407 habitantes em 2015 (dados do IBGE). Isso significa que, em 2015, mais 35.302 pessoas passariam a morar na RA VIII.

Com relação ao crescimento populacional, Salvador possuía 2.443.107 habitantes em 2000, valor que passaria para 2.926.442 habitantes em 2015, correspondendo, assim, a um crescimento que representa quase meio milhão de pes- 
soas na cidade. Também era previsto o crescimento populacional na RA VIII, de modo que, em 2000 , sua população correspondia à aproximadamente $4,3 \%$ da população de Salvador. Em 2015, passaria a corresponder a aproximadamente 4,8\%.

A densidade populacional bruta na RA VIII era de 94 hab/ha, em 2000, e, para 2015, ficaria em torno de 125 hab/ha. Comparando os valores, é possível notar que a RA VIII possuía uma densidade populacional bruta maior que a total de Salvador em 2000 (que era de 79 hab/ha), continuando maior em 2015 (95 hab/ha em 2015 para Salvador e 125 hab/ha para a RA VIII).

\subsection{Densidade e déficit domiciliar}

Em 2000, Salvador possuía uma população de 2.443.101 habitantes, 651.293 domicílios e uma densidade domiciliar de 3,75 hab/dom. De acordo com dados do IBGE, no ano 2010, Salvador possuía uma população de 2.675 .656 habitantes e 858.496 domicílios. Sendo assim, a densidade domiciliar para esse ano corresponde a 3,11 habitantes por domicílio. Esses dados mostram que aumentou o número de domicílios de 2000 para 2010, surgindo mais 207.203 novos domicílios na cidade, aumento que corresponde a cerca de $24,13 \%$ do total de domicílios de 2010, enquanto a relação habitantes por domicílio (densidade domiciliar) diminuiu de 3,75 hab/dom para 3,11 hab/dom de 2000 para 2010.

A partir dos dados relativos a ao ano de 2000, do PDDU (2004), é possível saber o déficit domiciliar na Região Administrativa 8 de acordo com as faixas de renda em salários mínimos. A faixa de população que possui renda de 0 a 5 salários mínimos corresponde a $78 \%$ do déficit domiciliar, correspondendo a $12,27 \%$, e a superior a 10 salários mínimos corresponde a 9,36\%. De acordo com esses dados, a classe baixa corresponde a mais da metade do déficit domiciliar, ou seja, o maior déficit está na faixa de população que menos possui condições de adquirir moradia por conta da renda. Analisando os dados, é possível notar que, em relação às outras regiões administrativas, a RA VIII é a que possui menor déficit domiciliar, valor que corresponde a aproximadamente $1,47 \%$ do déficit total.

\subsection{Demanda domiciliar}

Diante dos dados apresentados, em 2015, a população da RA VIII seria de 140.407 habitantes. Em 2000, esse valor era de 105.105 habitantes. Assim, em 2015, haveria mais 35.302 moradores na RA VIII. Esse valor representa a população adicional para o bairro, importante para o cálculo da demanda domiciliar. Além desse valor, também faz parte do cálculo da demanda a população que não possui moradia, que, no caso da RA VIII, corresponde a 619, segundo a tabela "Distribuição do Déficit Domiciliar por Faixas de Renda e Região Administrativa - 2000", presente no PDDU 2004. Dessa forma, o total de população que corresponde ao déficit domiciliar na RA VIII é de 35.921.

A densidade domiciliar de 2010 corresponde a 3,11 hab/dom. Avaliando esse dado, é possível calcular que, no ano de 2015, existiriam 45.146 domicílios 
na RA VIII. Esse valor corresponderia a cerca de 4,79\% da quantidade de domicílios total da cidade, que seriam 940.978 domicílios no ano 2015.

Do total de população que corresponde ao déficit domiciliar na RA VIII (35.921), 78,35\% estão na faixa de renda de 0 a 5 salários mínimos, cerca de 28.145 pessoas; $12,27 \%$ estão na faixa de renda de 5 a 10 salários mínimos, cerca de 4.408 pessoas, e 9,36\% na faixa de renda maior que 10 salários mínimos, cerca de 3.368 pessoas. Para cálculo do número de unidades residenciais, foi considerado $40 \mathrm{~m}^{2}$ para a população de classe baixa, com 5 pessoas por domicílio; $70 \mathrm{~m}^{2}$ para a população de classe média, com 4 pessoas por domicílio, e $100 \mathrm{~m}^{2}$ para população de classe alta, com 3 pessoas por domicílio. A partir disso, os resultados mostram que a demanda corresponde a 5.629 unidades para a classe baixa, 1.102 unidades para a classe média e 1.123 unidades para a classe alta, totalizando 7.854 unidades residenciais, sendo necessário um total de 41,46 ha para a construção de todas essas moradias.

A partir dos estudos demográficos, ficou previsto que, para o ano de 2015, seriam necessárias 7.854 unidades habitacionais para suprir a demanda domiciliar total (para todas as classes sociais), o que aponta a necessidade de cerca de 41,46ha de área livre na Região Administrativa Pituba/Costa Azul. Praticamente todos os bairros que compõem essa Região Administrativa já estão densamente ocupados, possuindo poucas áreas livres que, de fato, possuem potencial construtivo, o que se justifica pela própria expansão urbana que ocorre atualmente na cidade, direcionada para a Avenida Paralela e Aeroporto. Além disso, é possível notar que as poucas áreas livres vêm sendo ocupadas de modo intenso por empreendimentos voltados para atender demandas das classes mais favorecidas.

Como as outras classes (média e alta) possuem um déficit muito menor do que a classe baixa, é possível que, por meio das medidas previstas no PDDU 2007, com as restrições de uso do solo, permitindo que se construam edifícios cada vez mais altos, se consiga suprir esse déficit de maneira significativa. 0 caso do déficit na zona cuja população é de baixa renda é de fato o mais crítico, e menos considerado como prioridade pelo poder público, uma vez que este tem privilegiado cada vez mais as decisões urbanas voltadas para o mercado imobiliário, sendo assim, automaticamente, para as classes mais favorecidas. Segundo Villaça (2003, p. 341),

[...] toda exclusão social (inclusive as não formais ou não oficiais) só é possível a partir de uma dominação e esta é uma dominação política, ideológica e, principalmente econômica. O chamado mercado é o principal instrumento de dominação e exclusão econômica e quase sempre apresenta uma manifestação espacial. É, portanto um instrumento de segregação.

Assim, a população carente acaba por vivenciar de modo mais cruel as consequências desta realidade com múltiplos problemas. Segundo Maricato (2003, p. 158), 
[...] a orientação de investimentos dos governos municipais revela um histórico comprometimento com a captação da renda imobiliária gerada pelas obras (em geral, viárias), beneficiando grupos vinculados ao prefeito de plantão. Há uma forte disputa pelos investimentos públicos no contexto de uma sociedade profundamente desigual e historicamente marcada pelo privilégio e pela privatização da esfera pública.

Parte da população vive em condições muito precárias, não tendo acesso à moradia digna e à qualidade de vida. Esse fato se refletiu no estudo do crescimento populacional e demanda por moradia para o bairro (análise demográfica da área apresentada nesta pesquisa). Os resultados dos dados pesquisados mostram que exatamente a população de baixa renda é a que compõe a maior porcentagem nesse déficit domiciliar (78,35\% na RA VIII). Esse valor equivale a cerca de 28.145 pessoas sem moradia, no ano 2015, na Região Administrativa Pituba/Costa Azul.

Segundo Maricato (2003, p. 157),

[...] a maior tolerância e condescendência em relação à produção ilegal do espaço urbano vem dos governos municipais aos quais cabe a maior parte da competência constitucional de controlar a ocupação do solo. A lógica concentradora da gestão pública urbana não admite a incorporação ao orçamento público da imensa massa, moradora da cidade ilegal, demandatária de serviços públicos.

Para grande parte da área demarcada como ZEIS (com exceção apenas dos conjuntos produzidos pelo programa Minha Casa Minha Vida, que possuem condições mínimas de habitabilidade em relação ao restante, e edifícios que também possuem mínimas condições de moradia, onde as famílias podem construir pavimentos uns sobre os outros com o passar dos anos), o mais adequado seria promover uma desapropriação, nos casos mais críticos (onde os melhoramentos são inviáveis) e construir edificações com qualidade e capazes de suprir o déficit de moradia da classe baixa.

Uma alternativa a se pensar seriam edifícios residenciais para essa classe social, já que o programa Minha Casa Minha Vida constrói apenas poucos pavimentos por edificação e apresenta, por sua vez, uma série de problemas, por não serem acompanhados de infraestruturas diversas que possibilitem a construção de uma vida produtiva e saudável para seus moradores. O fato de o programa Minha Casa Minha Vida ser a única política pública voltada para resolver a questão da habitação no Brasil, no caso, direcionada à população de baixa renda, que, por sua vez, constitui grande parte da população, constitui-se como um gravíssimo problema para que soluções eficazes sejam tomadas nessa área e novas possibilidades possam surgir.

Analisando essas possibilidades, é possível notar que o PDDU 2007 também não permitiria esse tipo de solução, já que determina apenas $C A B$ de 1,50 para as ZEIS. Porém, por conta do tamanho do déficit, talvez apenas com medidas desse tipo fosse possível, além de toda a população carente permanecer onde está, também organizar, inclusive com qualidade e infraestrutura, o espaço urba- 
no desse trecho, integrando-o ao bairro e à cidade.

Os desafios para suprir as necessidades dessas áreas extremamente carentes são grandes, e, diante de todas essas análises, fica claro que as medidas previstas no Plano Diretor da cidade de Salvador não conseguem dar soluções adequadas para esses casos mais extremos.

\section{Considerações finais}

Ao estudar o zoneamento previsto pelo PDDU 2007 para o Costa Azul, é possível perceber que diversos fatores particulares presentes no bairro atuam como limites e reguladores dos parâmetros que foram definidos para uso e ocupação do seu solo. Entre esses fatores, está o fato do bairro possuir grande parte da sua área geográfica classificada como área de borda marítima, sendo esta uma área da cidade que possui parâmetros especiais para uso e ocupação. Também possui a presença de elementos naturais marcantes, que são classificados dentro das áreas de proteção paisagística, além da presença do Rio Camarajipe, que corta o bairro. Além disso, há duas áreas de interesse social (ZEIS), o que demonstra que parte do bairro não possui uma estrutura urbanística nem regularização de lotes e boa qualidade das construções, variando em suas tipologias desde o conjunto Minha Casa Minha Vida a barracos feitos de papelão, ou espaços minúsculos, com problemas diversos e alto grau de inabitabilidade.

O Costa Azul é um dos bairros que possui pouquíssimos terrenos vazios, e que, por conta disso, já passa por um processo de substituição de edificações, ao invés de expansão, com a construção de prédios residenciais mais altos do que os atuais, com maior quantidade de apartamentos e também com menor área por apartamento. Assim, o número de unidades residenciais tem aumentado por lote, e o tamanho dos apartamentos construídos tem diminuído, diminuindo, em muitos casos, também a qualidade da moradia, até mesmo para as classes média e alta. Desse modo, nota-se que as pressões do mercado imobiliário sobre a cidade vêm depredando a qualidade de vida da população em várias escalas.

O processo de compensação do déficit habitacional para o caso do Costa Azul tem sido feito dessa maneira, pois as áreas vazias presentes no bairro atualmente são os poucos lotes que ainda restam e áreas que possuem valor urbano e paisagístico. Apesar do número de domicílios ter crescido, além de ter ocorrido também o crescimento da população, não significa que todos eles realmente são moradias, ou seja, que sejam imóveis adquiridos e habitados.

Apesar de estar ocorrendo um processo de construção e renovação das edificações no bairro, esse fato pode não contribuir para a diminuição desse déficit por conta de outras questões, como as condições da população para adquirir sua moradia, ou mesmo o predomínio de construções voltadas para atender demandas de serviço (empreendimentos mais recentes construídos na Avenida Arthur Azevedo). Principalmente porque mais da metade da população que representa o déficit domiciliar na RA VIII encontra-se na classe baixa, condição que a exclui das poucas possibilidades existentes. 
Além dos entraves encontrados no processo do mercado da construção civil, onde o que está sendo construído no bairro não ajuda a suprir de forma significativa esse déficit, a questão da moradia no bairro Costa Azul apresenta uma situação ainda mais complicada. As áreas onde se concentra a população de baixa renda são de invasão, ou seja, áreas desprovidas de legalização urbanística, fator que, por sua vez, determina uma série de problemas ligados à infraestrutura urbana. A condição extremamente precária das habitações e a forma como estão dispostas no local (de maneira totalmente desorganizada e insalubre) impedem que se viabilizem as medidas que estão previstas pelo PDDU 2007 para áreas de interesse social (ZEIS), pois, de fato, as condições reais encontradas nesses locais são piores do que as que foram consideradas no estabelecimento das diretrizes para tais zonas. Essas medidas são regularização fundiária, revitalizações e projetos de infraestrutura, que geralmente são adotados com objetivo de qualificar e consolidar os locais ocupados pela população de baixa renda. Porém essas medidas não funcionariam como solução para as áreas demarcadas como ZEIS no Costa Azul (Paraíso Azul e Recanto Feliz), por conta do nível de pobreza encontrado nessas áreas, como já descrito anteriormente.

Ao se propor um exercício de imaginar soluções, mesmo que de modo simplificado e hipotético, para questões urbanas tais como a problemática descrita neste artigo, com relação às ZEIS presentes no bairro Costa Azul, por exemplo, percebe-se a proporção das incoerências e rupturas presentes no processo de planejamento urbano para a cidade de Salvador num passado recente e que se estende à atualidade, onde medidas determinadas pelo Plano Diretor ou pela Lei de Ordenamento do Uso e Ocupação do Solo (LOUOS) são inviabilizadas de acontecer na prática e permitir uma melhor gestão do espaço e, consequentemente, agregarem mais qualidade de vida à população.

Desse modo, percebe-se claramente que existe uma série de limitações com relação à tomada de decisões resolutivas para a cidade de Salvador, o entendimento aprofundado de suas particularidades e problemática urbana, de modo que o planejamento acaba por ser superficial e desconectado da dimensão real das questões às quais precisa apresentar soluções.

Também fica claro que, apesar da complexidade dos problemas urbanos relacionados à habitação, atualmente, nos centros urbanos, sobretudo para a população carente, observa-se que muitas questões se agravam por falta de pensar um planejamento estratégico com alternativas lógicas para essas áreas, privilegiando o diálogo e a participação das comunidades nos processos de mudança imateriais e materiais por uma simples questão de prioridade e interesse, voltados para a "ditadura" do capital imobiliário.

A dinâmica urbana, os processos de ocupação do solo e os problemas socioeconômicos e ambientais continuam a acontecer de maneira cada vez mais acelerada em relação às previsões e às medidas de planejamento urbano, uso e ocupação do solo adotado nas cidades brasileiras. Salvador se constitui num caso crítico de alta segregação socioespacial, como pode ser observado ao se estudar o processo de planejamento da cidade desde os primeiros planos urbanísticos 
aos mecanismos vigentes atualmente, ou simplesmente observando sua dinâmica urbana de modo cotidiano.

Observa-se um processo de planejamento fragmentado, deficiente e, muitas vezes, incoerente, até mesmo quando se trata das áreas mais nobres da cidade, sejam elas novas ou antigas, como os processos de desvalorização ocorridos no bairro do Comércio, a cenarização desvitalizada que vem caracterizando o Pelourinho atualmente, a expansão urbana, sem considerar de modo efetivo a questão ambiental, ao longo da Avenida Paralela, dentro outros casos problemáticos, o que afasta Salvador, cada vez mais, de ser uma cidade inclusiva, sustentável, com participação popular e democracia, com valorização real de seu patrimônio material e imaterial, dentre outras questões fundamentais com relação à função social da cidade.

\section{Referências}

BASE SICAR. Conder. Sistema de Informações Geográficas Urbanas do Estado da Bahia. Disponível em: <http://www.informs.conder.ba.gov.br/Base_Dados/ BAD_dados_cartograficos.asp>. Acesso em: 12 mar. 2016.

MARICATO, E. Metrópole, legislação e desigualdade. Estudos Avançados, v. 17, n. 48, p. 151-167, 2003. Disponível em: <http://dx.doi.org/10.1590/s010340142003000200013>. Acesso em: 12 mar. 2016.

PREFEITURA MUNICIPAL DO SALVADOR. Lei Ordinária 6586/2004. Salvador, 2004. Disponível em: <www.leismunicipais.com.br>. Acesso em: 12 mar. 2016.

Plano Diretor de Desenvolvimento Urbano do Município de Salvador, 2008. Lei $N^{\circ} 7.400 / 2008$. Salvador: Diário Oficial do Município n 4601 de 23 a 25 de fevereiro de 2008, PMS, 2008.

SANTOS, E. et al. O Caminho das Águas em Salvador: Bacias Hidrográficas, Bairros e Fontes. Salvador: CIAGS/UFBA; SEMA, 2010.

VILLAÇA, F. Segregação Urbana e Justiça (ou A justiça no injusto espaço urbano). Revista Brasileira de Ciências Criminais, v. 11, n. 44, p. 341-346, 2003. Disponível em: <https://www.ibccrim.org.br/rbccrim/21-/?ano_filtro=2003>. Acesso em: 12 mar. 2016. 